\title{
PERFORMANCE ENHANCEMENT OF SOLAR PHOTOVOLTAIC PANEL USING AUTOMATED SOLAR PANEL CLEANER
}

\section{ADITYA R. KULKARNI, KEDAR N. MUJUMDAR, VAIBHAV R. PATIL, NIKHIL S. MAHALE \& MAANAS P. SINDKAR}

Vishwakarma Institute of Technology, 666, Upper Indira Nagar, Bibwewadi, Pune 411037, Maharashtra, India

\begin{abstract}
In recent years, India has increased its solar power installation capacity and utilizes around $7.5 \%$ of the world's total solar energy consumption. Extensive research is in progress to utilize better materials for solar photovoltaic panels. The present study focuses on an equally important and rather neglected aspect of cleaning the solar photovoltaic panels for achieving better output.

Manual cleaning of the panels is often difficult at many locations and suffers from some inherent drawbacks of manual operation. In the present experimental study, an automated cleaning system using Arduino and motor controller has been implemented for cleaning of solar photovoltaic panels. The performance of the panels equipped with the aforementioned cleaning system is compared with panel not using this mechanism. The experimental data reveals that the panels with automated cleaning systems were able to produce more power output up to an extent of $25 \%$ of the rated output. There is thus a wide scope for meeting the increased energy requirements at a reduced installation cost to achieve the targeted power production. Application of the proposed system can yield reliable power output at reduced maintenance costs and shows feasibility for installation at potential locations.

KEYWORDS: Automated, Cleaning Mechanism, Solar Photovoltaic Panel, Dust Density, Rated Output, Power Losses, Efficiency
\end{abstract}

Received: Jun 08, 2020; Accepted: Jun 28, 2020; Published: Sep 11, 2020; Paper Id.: IJMPERDJUN20201161

\section{INTRODUCTION}

Conventional and non-renewable sources of energy continue to diminish, suffer from ever rising prices and higher environmental emissions. Renewable energy sources have thus become popular in recent time and extensive research is taking place regarding renewable energy sources. Out of these, solar energy has found the largest interest is beginning to shift towards non-applications in terms of harnessing heat and electricity from solar radiations. With this trend in the past few years there have been a lot of problems, some of which have been resolved and some have been left unresolved. Extensive research is in process to search new materials for improving the efficiency of photovoltaic cells. Equal attention should be paid towards maintaining the conversion efficiency of photovoltaic cells.

Solar panels are usually placed in the region with high in solation levels. The performance of photovoltaic cells is affected by temperature, intensity of radiation due to sun, angle at which solar panel is mounted and the amount of dust settlement on the panel. Photovoltaic cells, when used as a medium of energy collection, show significant variation between the rated performance and the actual energy output. Efficiency of the photovoltaic cells reduces exponentially due to dust deposition on the panel surface. Apart from some other problems reducing 
the efficiency, dust settlement is a major factor, which is comparatively easy to overcome, but still which is completely ignored by the end users. Dust settlement depends on The local factors like terrain and ecological factors like ambient temperature, rainfall, and other elements. Change in the performance of the solar panel can be monitored by studying its VI characteristics.

The present work deals with the problem of dust accumulation on solar panels. Solar power is a widely used type of non-conventional energy sources, mainly since it is a nearly infinite source of energy. For the Sun to deplete its hydrogen core it will take 4.5 to 5.5 billion years. Hence solar panels are widely used and are a long-term investment. Though solar panels are very useful, they are also associated with some practical difficulties. The panels are quite inefficient, can form micro cracks, develop hot spots on the panels and are prone to dust settlement.

Even though dust settlement is a geographic action, the loss in efficiency is exponential. Nowadays it is common to see solar panels being installed on top of buildings or in places which have direct sunlight throughout the day. Solar panels are most efficient during peak sun hours. The peak hours also vary geographically, usually lasting 3-6 hours in a day. The panels should be at the highest efficiency during these peak sun hours. Being an inefficient medium of harnessing useful solar energy, there are on-going efforts to increase the efficiency of the solar panels. The solution to these problems may look easy but are quite convoluted. As dust keeps collecting on the panel, the efficiency reduces at an exponential rate. The rate of reduction of efficiency eventually decreases, as the panel gets saturated with dust. At least cleaning them two times a month is necessary and if the climate conditions are harsh or if the panels are placed in dusty areas or near a desert, the cleaning process should be done on a regular basis. One may think that simply cleaning the panels manually is an option; however, the panel's accessibility must be taken into consideration. Manual cleaning has disadvantages like risk of staff accidents and damage to the panels, movement difficulties, poor maintenance, and other factors. The automatic dust cleaning system of solar panels has taken to overcome the difficulties arisen in the traditional cleaning and produces an effective, non- abrasive cleaning method. It prevents the irregularities in the productivity due to the deposition of dust. An automated mechanism would be helpful in cleaning the panels. The authors of this study focused on solving the aforementioned challenges, by creating an automated mechanism designed to clean the surface of the panel of any settled dust. The mechanism uses two lead screws propagating the cleaning brush, two high speed motors, and water pump all working in tandem to clean the panel. The brush, in the first part of the cycle, moves across the panel while cleaning the surface. During its return to its original position, no cleaning is done.

\section{LITERATURE REVIEW}

A major contributor in the inefficiency of solar panels was the accumulation of dust, water and moss, which would obstruct the radiations collected by the panel. The experiment was carried out using different materials for obstructing the panel, while a spotlight was used to deliver radiation to the panel. It was found that accumulation of dust could lead to an $85 \%$ drop in output. Accumulation of water on the surface may lead to a further 4-5\% drop in the output of the solar panel [1]. One research effort determined the losses due to dust accumulation and other geographical factors of output of the photovoltaic cell by comparing the I-V characteristics of panels subjected to different conditions. The effect of rainfall on the panel is subjective to the conditions that were present before the rainfall. Rainfall may wash out the dust from the panel; however dust that was present during the evaporation of water from the panel may cause the dust to adhere better to the panel [2]. Another research paper portrayed the idea that analyzed how everyone is interested in using the renewable and sustainable sources of energy and the ideas of solar home systems is becoming popular day by day. This paper 
explores in detail the poor efficiency of solar panels and how dust collected on the surface of the cells impacts them claiming a decrease an in output of $35 \%$ per month [3].

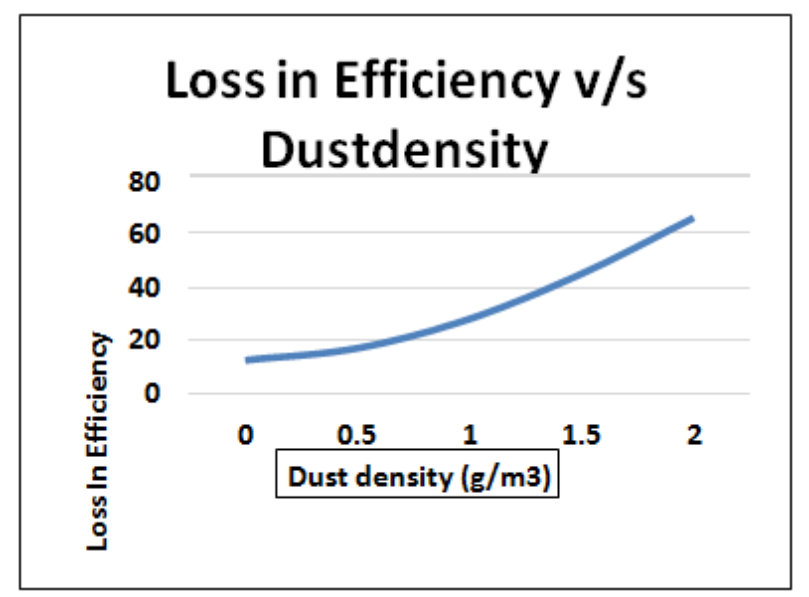

Figure 1: Graph of Loss in Efficiency vs. Dust Density [4].

The cited graph shows that as the density of accumulated dust increases, the loss in efficiency of the panel also increases. Another research showed the dust particle accumulation affects on outdoor photovoltaic module. The study focused on the sensitivity of the polycrystalline silicon photovoltaic module towards industrial dust deposition under tropical climate conditions. Results showed losses up to $64 \%, 42 \%, 30 \%$, and $29 \%$ for coal, aggregate, gypsum, and organic fertilizer dust, respectively. It was also demonstrated that PV module performance deteriorated with temperature rise owing to heat dissipation caused by dust accumulation [5]. In a study on the outputs of panels with dust accumulated on them, conducted in Palo Alto, California, it was observed that a $2 \%$ reduction in the output had occurred, as compared to the clean solar panels [6]. In a study conducted by Google, two panels in different orientations were observed. After cleaning the panels, it was observed that a flat panel showed a significant increase in output, as compared to the tilted panel. This shows that dust accumulates in a larger amount on flat panels, about twice as much [7]. An experiment conducted in Roorke, India, an average $8 \%$ reduction of transmission of radiation to the panel was observed after a period of 10 days. The panel was inclined at an angle of $45^{\circ}[8]$.

In a study exploring the design of an automatic cleaning system for solar panels, it was noted that, in tropical countries such as India, most large solar panel arrays are installed at locations that are dusty, which would cause the wind to deposit said dust and other obstructions onto the panels. The cleaning system was propagated by a rack and pinion arrangement. A drop of 50\% was recorded in panels that were not cleaned in a period of one month. With the cleaning system installed, the output was shown to be $30 \%$ more than that of the dust accumulated panel [9]. It is important to clean the PV modules regularly to gain the maximum power output, while considering factors like bird droppings, dust, pollen and mud. It was estimated that the power losses were up to 30 to 40 per cent of the maximum power consumptions. This research suggests a system (using a rack and pinion gear mechanism) that could reduce the power losses up to $10 \%$ of the maximum power consumption [10]. A different mitigation approach was reported, in which NASA produced a selfcleaning solar panel technique that worked by a mechanism that sensed the presence of dust on solar panels [11].

\section{METHODOLOGY}

The details of the automated solar panel cleaner are described in the following sections. 
Details of the Components Used

Table 1: List of Components Used

\begin{tabular}{|c|c|c|c|c|}
\hline Sr. No. & Components & Specification & Dimensions & Quantity \\
\hline 1 & Lead Screw & Pitch $=2 \mathrm{~mm}$ & Length $=50 \mathrm{~cm}$ & 2 \\
\hline 2 & Motors & 775 DC motors $12 \mathrm{~V}$ & - & 2 \\
\hline 3 & Coupler & Flexible Coupling & $8 \mathrm{~mm}$ to $6 \mathrm{~mm}$ & 2 \\
\hline 4 & Bearing & $\begin{array}{l}\text { Pillow Block Insert Bearing } \\
\text { KP08 }\end{array}$ & $\begin{array}{l}\text { 10mm Bore Inner Ball } \\
\text { Mounted }\end{array}$ & 4 \\
\hline 5 & Solar Panel & 8 Watts $18 \mathrm{~V}$ & $36 \times 28 \mathrm{~cm}$ & 1 \\
\hline 6 & Water Pump & 12V Centrifugal & - & 1 \\
\hline 7 & Arduino & Uno R3, CH340G & - & 1 \\
\hline 8 & Motor driver & L298D & - & 1 \\
\hline 9 & $\begin{array}{l}\text { Solar Charge } \\
\text { Controller }\end{array}$ & Micro-controller 12V/10A & - & 1 \\
\hline 10 & Wiper & Rubber wiper & Length $=28 \mathrm{~cm}$ & 1 \\
\hline 11 & Water tube & Flexible Rubber Tube & $\begin{array}{c}\text { Diameter }=10 \mathrm{~mm} \\
\text { Length }=120 \mathrm{~cm}\end{array}$ & 1 \\
\hline 12 & Battery & $\begin{array}{c}12 \mathrm{~V} \\
1.3 \mathrm{Ah} / 20 \mathrm{hr}\end{array}$ & - & 2 \\
\hline
\end{tabular}

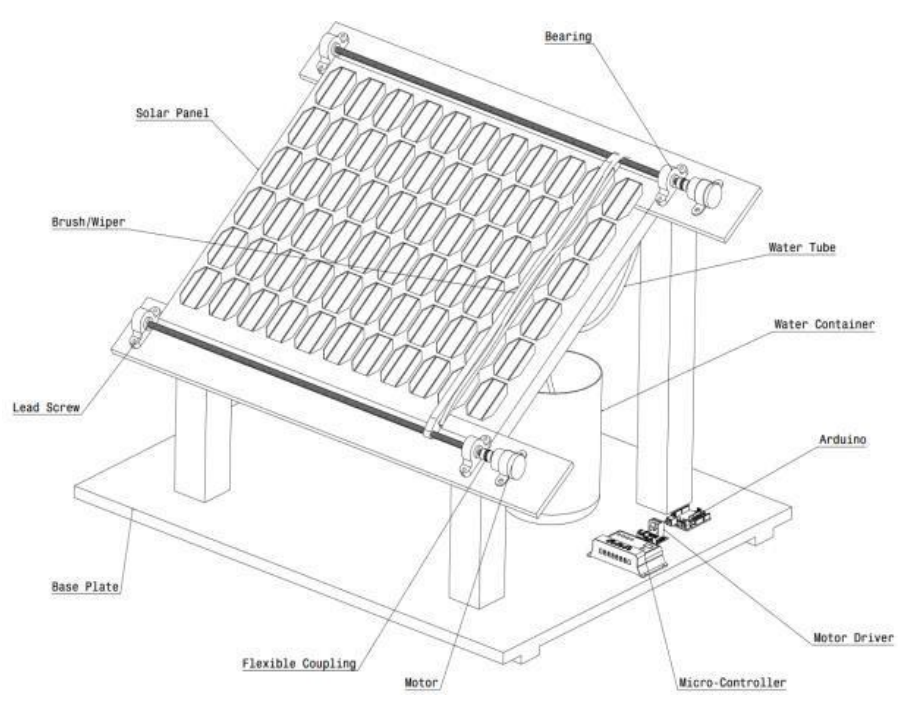

Figure 2: Schematic of the Cleaning Mechanism.

Description of the Design and Working

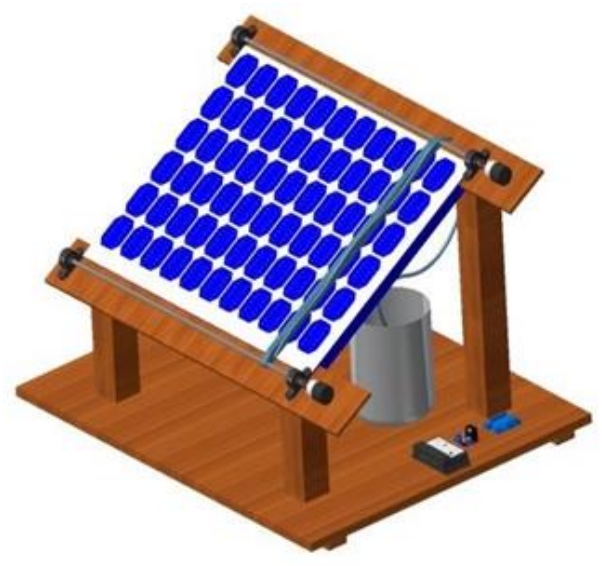

Figure 3: CAD Model of the Cleaning Mechanism. 
The entire system is mounted on a wooden base plate. The solar panel is mounted on the base plate and kept inclined at $30 \mathrm{o}$ to the horizontal. It is better to mount the panel in an inclined position, as dust accumulation is less in this position, rather than in a flat position. A wiper is mounted parallel to the panel, while a water tube, which is connected to the water pump, supplies water to the wiper. The water pump lifts water from a container placed on the base plate and supplies to the water tube, connected to the wiper. There are multiple miniscule holes located at equal distances on the water tube, through which the water sprays out at high pressure, thereby cleaning the solar panel. Both ends of wiper are connected to two separate lead screw mechanisms. The lead screws are connected to the motors using flexible couplings. The lead screws are fixed to the system, using bearing so neither end, in such a way that they are allowed to rotate. The output terminals of the panel are connected to The solar charge controller. The solar charge controller continuously charges the battery, while also providing the motors with power. The solar charge controller, the Arduino board, and the motor driver circuit are connected to the baseplate.

As the motor rotates, the lead screw converts the rotational motion of the motor shaft into the linear motion of the wiper across the panel. The motor shaft and the lead screw are connected using a flexible coupling. Flexible couplings are used in order to dampen the vibrations produced due to small errors in the fitting. Simultaneously, as the wiper moves, water is drawn from the container by the pump, and is sprayed onto the surface of the panel. In the first half of the cycle, the wiper moves across the panel, while the tube sprays water over the surface. In the next half of the cycle, the wiper returns to its original position. No cleaning is done in the second half of the cycle.

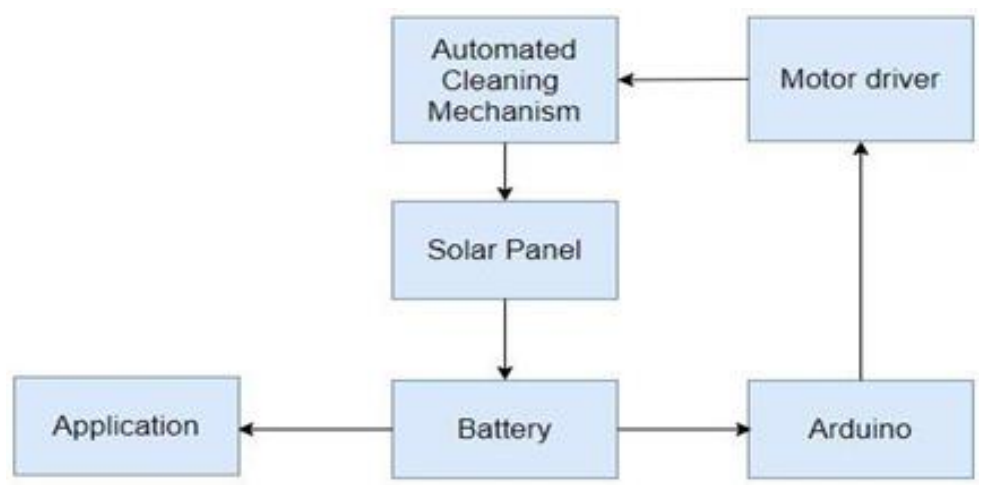

Figure 4: Flow Chart Showing the Electrical Connections.

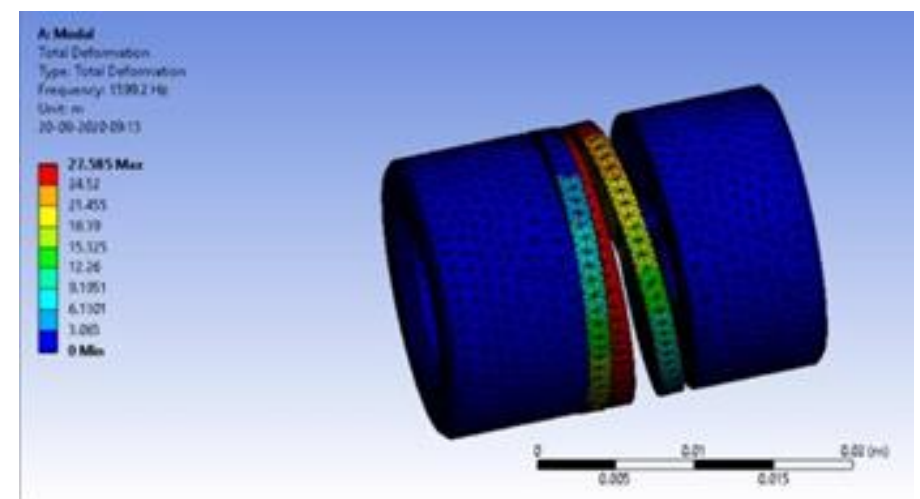

Figure 5: Vibrational Analysis of Flexible Coupling. 


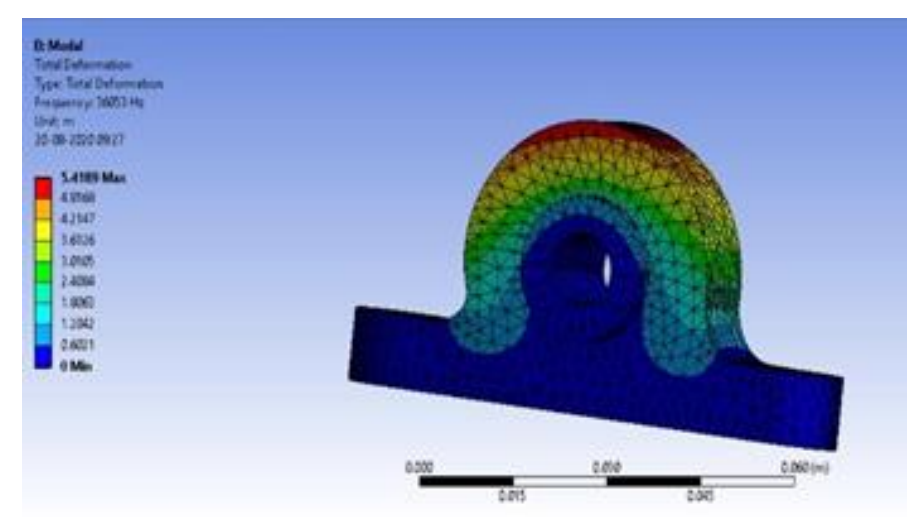

Figure 6: Vibrational Analysis of Bearing.

For the cleaning mechanism, the most critical parts are flexible coupling and bearings. The stresses experienced by the various parts of the mechanism are not as significant as vibrations experienced by various parts. Hence, Modal analysis of flexible coupling and bearing is performed. From the figure 4, it can be inferred that some part of the solar panel output is used to charge the battery, while the rest is used for its desired application. The battery in turn powers the Arduino board and motor driver circuit, which ultimately brings about the movement of the cleaning mechanism. The output of the solar panel is stored in the battery, through the solar charge controller. Further, the battery output is used to power the motors connected to the lead screw. If the output of the solar panel is insufficient to run the motors, they are powered by power stored in the battery. The battery is also used to power the Arduino board. The Arduino board is further connected to the motor driver (L298D). The to and fro motion of the wiper is controlled by the program uploaded to the Arduino board. The Arduino is programmed to run periodically, after a period of 15 days. The motor controller is used to change the direction of rotation of the motors according to the program.

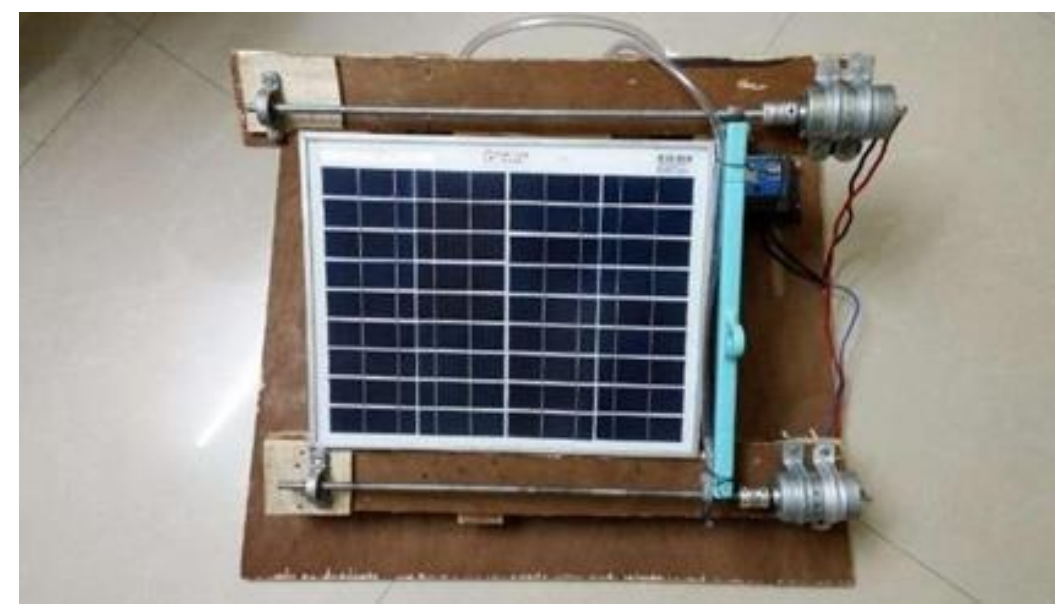

Figure 7: Top View of the Cleaning Mechanism.

The solar panel is placed in an open environment, however, for the purpose of recording the readings, a source of light, capable of simulating equal in solation, is made incident upon the surface of the solar panel. The readings taken comprise the output current and voltage of the solar panel. The readings were taken periodically, every 15 days, over a total period of 60 days. The panel output wattage was calculated, and compared with the rated wattage of the panel. All following readings are taken with respect to the rated wattage. The readings were taken on two separate panels, out of which one was cleaned regularly using the automated cleaning mechanism, and the other was left without cleaning. Discussion of these readings is done in the following text. 


\section{Calculations}

The performance of the solar panel can be studied by its I-V characteristics. The readings of the output voltage and current are taken by using a multimeter. Voltage and current for each of the reading are noted simultaneously.

The power output of the panel is calculated as follows:

$\mathrm{P}=\mathrm{V} . \mathrm{I}$

Where,

$\mathrm{P}=$ Power (in Watt),

$\mathrm{V}=$ Voltage (in Volts),

$\mathrm{I}=$ Current (in Ampere)

For a sample reading

$V=15.38 V, I=0.32 A$

$P=V . I$

$P=4.92 W$

The efficiency of panel is calculated with reference to the maximum rated power output of the panel. The maximum rated output of the panel is $8 \mathrm{~W}$.

$$
\text { Ef fi.cien.c.v }=\frac{\text { CalculatedPowerOut putofthePanel }}{\text { Maximum Power Output of thePanel }} \times 100
$$

For a sample reading

$$
\begin{aligned}
& \text { Efficiency }=\frac{4.92}{8} \times 100 \\
& \text { Efficienc }=61.25 \%
\end{aligned}
$$

\section{RESULTS AND DISCUSSION}

The following tables and graphs discuss the relation of power with efficiency

Table 2: Panel 1 (Without Cleaning Mechanism)

\begin{tabular}{|c|c|c|}
\hline Days & Power (Watts) & $\begin{array}{c}\text { Efficiency } \\
\text { (against 8W } \\
\text { rated output) }\end{array}$ \\
\hline 1 & 7 & 87.5 \\
\hline 15 & 5.9 & 73.75 \\
\hline 30 & 5.11 & 63.875 \\
\hline 45 & 4.9 & 61.25 \\
\hline 60 & 4.8 & 60 \\
\hline
\end{tabular}


Table 3: Panel 2 (Equipped with Automated

Cleaning Mechanism)

\begin{tabular}{|c|c|c|}
\hline Days & Power (Watts) & $\begin{array}{c}\text { Efficiency } \\
\text { (against 8W } \\
\text { rated output) }\end{array}$ \\
\hline 1 & 7 & 87.5 \\
\hline 15 & 6.9 & 86.25 \\
\hline 30 & 6.72 & 84 \\
\hline 45 & 6.724 & 84.05 \\
\hline 60 & 6.82 & 85.25 \\
\hline
\end{tabular}

To begin with, both the panels produced an output of 7 watts, which is $87.5 \%$ of the maximum rated output. From Table 2, it is observed that the efficiency drop after 60 days was $27.5 \%$, for the panel that was not cleaned regularly. From Table 3, a drop of $2.25 \%$ in the efficiency was recorded, for the panel that was cleaned regularly by the mechanism every 15 days.

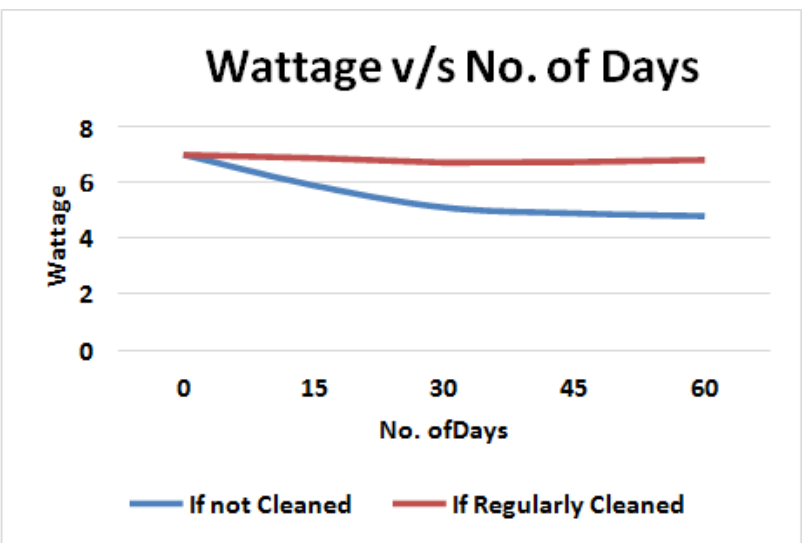

Figure 9: Graph of Wattage vs. Number of Days.

There is an obvious increase in the efficiency due to an increase in the output wattage. The variation of the panel output wattage over a period of 60 days is as shown in figure 9. From the graph it can be inferred that for the panel without the Cleaning mechanism, there is a significant reduction in the wattage output in the first 30 to 35 days, and then it becomes nearly constant, whereas for the panel with the cleaning mechanism, the wattage is nearly constant from the beginning.

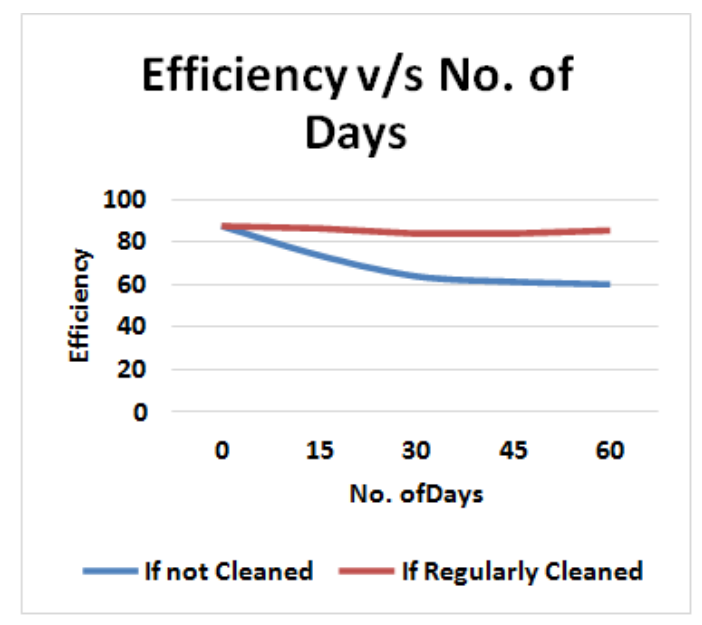

Figure 10: Graph of Efficiency vs. No. of Days. 
Figure 10 shows the variation in efficiency of the two panels over a period of 60 days. The graph reveals that the drop in efficiency is steeper for the panel 1 which was not cleaned; whereas the panel 2 cleaned using the automated cleaning mechanism shows a small drop in efficiency during 60 days. A considerable drop in efficiency is recorded during the first 35 days for the panel 1. Comparing the above two graphs, it can be inferred that by cleaning the panel every 15 days, the loss in efficiency can be reduced.

Comparing results of the present work with that of an earlier cited study [10], the mechanism used could increase the output of the solar panel by $30 \%$ using a cleaning mechanism, whereas the mechanism suggested by the present study conducted could increase the efficiency by $25.25 \%$. This study observed the panel output for duration of 60 days, at the end of which, an efficiency loss of $2.25 \%$ was recorded, against the rated output. This loss in efficiency can be attributed to environmental factors such as accumulation of water on the panel, or dust accumulation during two successive cleaning intervals, or due to the maintenance required by the mechanism.

\section{FUTURE SCOPE}

The advancements which can be made can make the more cost effective and will be able to clean more efficiently. The mechanism can be improved by employing solar tracking mechanism, which would allow the panel to face the sun at all times of the day. This study recorded observations on a small scale, using only one panel mounted in the mechanism; however it can be scaled up to a larger application, which may provide a better insight regarding the utility of the cleaning mechanism.

\section{CONCLUSIONS}

Manual solar panel cleaning is not very cost effective, and requires a lot of man power and labor to complete the task. The present experimental study could minimize the drop in output power from solar panel using automated cleaning mechanism and a frequency of cleaning after 15 days. The mechanism suggested shows a potential to overcome the problem associated with manual cleaning in a simple and cost-effective manner. In spite of some future scope for improvement, the proposed mechanism attempts to enhance the efficiency of solar photovoltaic panels, and contribute to the energy sector in the best possible way.

\section{REFERENCES}

1. Shaharin Anwar Sulaiman, Atul Kumar Singh. et. al, "Influence of Dirt Accumulation on Performance of PV Panels", The International Conference on Technologies and Materials for Renewable Energy, Environment and Sustainability,TMREESI4.

2. Abhishek Rao, Rohit Pillai. et. al, "Influence of dust deposition on photovoltaic panel performance", 4th International Conference on Advances in Energy Research 2013, ICAER2013.

3. Sari-Ali, I., B. Chikh-Bled, and B. Benyoucef. "Effect of shading on the performance on solar photovoltaic." Int J ApplEng Res Dev (IJAERD) 4.2 (2014): 41-8p.

4. Md.Mizanur Rahman, Md. Aminul Islam. et. al, "Effects of Natural Dust on the Performance of PV Panels in Bangladesh", I.J. Modern Education and Computer Science, 2012, 10,26-32.

5. Ehsan Fadhil, Abbas Al-Showany, "The Impact of the Environmental Condition on the Performance of the Photovoltaic Cell", American Journal of Energy Engineering, Vol. 4, No. 1,2016. 
6. Alrwashdeh, Saad S. "Energy Output Evaluation from A Photovoltaic System at Different Selected Sites In Jordan." International Journal of Mechanical and Production Engineering Research and Development (IJMPERD), 2019. 9 (2): 467-476.

7. Yotham Andrea, Tatiana Pogrebnaya. et. al, "Effect of Industrial Dust Deposition on Photovoltaic Module Performance: Experimental Measurements in the Tropical Region”, Hindawi International Journal of Photoenergy, Volume2019.

8. G. B. Katz, "Effect of Dust on Solar Panel”,www.gregorybkatz.com/Home/effect-of-dust-on-solar-panels, 2008,27 April2011.

9. M. Moon, "Google Studies How Dirt Affects Solar Panel Efficiency”, PC Magazine: Good Clean Tech.,www.goodcleantech.com/2009/08/google_studies_how_dirt_affect.php,2009.

10. Issaadi, Wassila. "Control of a photovoltaic system by fuzzy logic, comparative studies with conventional controls: results, improvements and perspectives." International Journal of Intelligent Engineering Informatics 5.3 (2017): 206-224.

11. H.P.Garg, "Effect of dirt on transparent covers inflat-platesolarenergycollectors, "SolarEnergy,vol.15,pp.299-302,1977.

12. Abhishek Naik, NageshNaiket. al, “Automatic Solar Panel Cleaning System”, International Research Journal of Engineering and Technology(IRJET), Volume 06, Issue04.

13. Issaadi, Wassila, Malika Mazouzi, and Salim Issaadi. "Command of a photovoltaic system by Artificial Intelligence, comparatives studies with conventional controls: results, improvements and perspectives. " 2016 8th International Conference on Modelling, Identification and Control (ICMIC). IEEE, 2016.

14. Dr.G.Prasanthi ME, Ph.D, T.Jayamadhuri, "Effects Of Dust On The Performance Of Solar Panel And Improving The Performance By Using Arm Controller And Gear Motor Based Cleaning Method", IJISET - International Journal of Innovative Science, Engineering \& Technology, Vol. 2 Issue 9, September2015.

15. Retrieved from www.good.is/post/nasa-solves-solar-energy-s-dust-problem/. 